\title{
Incidence of inflammatory bowel disease in Scottish children between 1968 and 1983; marginal fall in ulcerative colitis, three-fold rise in Crohn's disease
}

\author{
J R BARTON, SANDRIA GILLON, AND ANNE FERGUSON \\ From the Gastro-Intestinal Unit, Western General Hospital and University of Edinburgh, Edinburgh
}

SUMMARY Linked hospital admission data for 1968-1983 were used to identify 723 children aged 16 years or less at the time of first admission to any Scottish hospital with an ICD coded diagnosis of Crohn's disease (282) or ulcerative colitis (441). The accuracy of the coded diagnoses was checked by examination of the hospital notes of 144 patients. The coded diagnosis was incorrect in 11/83 coded as Crohn's disease and 13/61 as ulcerative colitis; frequency of incorrect coding did not change significantly with time. Despite an $18 \%$ fall in the population aged $\leqslant 16$ during this time, the number of new cases of Crohn's disease rose from 10 in 1968 to 28 in 1983. Thus the recorded incidence of Crohn's disease in Scottish children has risen more than three-fold in 16 years, from 6.6 to 22.9 per million $(p<0 \cdot 0001)$, with no difference between the sexes. Parallel data for ulcerative colitis were rendered inaccurate by miscoding of infective gastroenteritis as colitis. In an attempt to reduce this source of error cases aged five years and under were excluded from analysis, resulting in an incidence of $19 \cdot 1$ cases per million aged six to 16 in 1968 and $15 \cdot 6$ in 1983 , not a significant change $(r=0 \cdot 42$, $p=0 \cdot 052$ ). When males and females were analysed separately, however, there was a significant decrease in the incidence of $\mathrm{UC}$ in male children $(r=-0.4, p=0.028)$, with no change for female children $(r=0 \cdot 1, p=0 \cdot 595)$.

Despite recent interest in adolescent medicine and recommendations on appropriate hospital and educational facilities for teenagers with chronic disease, ${ }^{1}$ there is scant information on the numbers of such patients and the quality of care currently provided. Particular problems are posed by children whose diseases require a multi-disciplinary approach to management; for example Crohn's disease, with reported features including delay in diagnosis, growth retardation, substantial morbidity, long spells as hospital inpatients and frequent recourse to surgery. ${ }^{2-4}$

In Scotland, all hospital admissions data are correlated in the SHIPS (Scottish Hospital In-Patient Statistics), and record linkage is used to combine multiple admissions of the same patient. ${ }^{56}$ The facility can provide information such as age, sex, date

Address for correspondence: Dr J R Barton, Gastro-Intestinal Unit, Western General Hospital, Crewe Road, Edinburgh EH4 2XU.

Accepted for publication 3 October 1988. of birth, hospital admission and discharge dates, operative procedures, and mortality for patients selected on the basis of an international classification of diseases (ICD) code. We have used SHIPS for the period 1968-1983, to establish the incidence of Crohn's disease and ulcerative colitis (UC) in Scottish children (aged $\leqslant 16$ years at first hospital admission). Accuracy of the coded data was assessed by examination of samples of hospital case records.

\section{Methods}

GEOGRAPHY AND POPULATION DETAILS

Population data by age and year were obtained from the General Register Office (Scotland). These statistics are derived from censuses, registrations of births and deaths and estimates of migration. Scotland has an area of 30405 square miles (7874895 sqkm) and a mean population of 5210141 between 1968 and 1983. The country is divided into 11 National Health Service administrative regions. These include 
Lothian (population 753400 ; area 678 sq miles; 1756 sqkm), containing the city of Edinburgh and its suburbs, with several teaching hospitals and two universities, and Highland region (population 186 400; area 9804 sq miles; 25392 sqkm), sparsely populated, with specialist health care provided from several small rural hospitals and one district general hospital in Inverness.

\section{IDENTIFICATION OF CASES}

Full record linkage in SHIPS was instituted during 1967. This enabled identification of multiple admissions of the same patient through unique demographic features throughout Scotland thus preventing overestimation of the number of new cases being diagnosed, and so the data base from 1968 to 1983 was searched. Dr J Webb provided to us a printout (without names) of all patients who, between January 1968 and December 1983: (a) were admitted to an NHS hospital in Scotland; (b) were aged 20 years or less at the time of admission; (c) had the coded diagnosis of Crohn's disease (ICD code for $1868-1975=563.0$, after ninth revision in $1975=$ 555.0-555.9), or ulcerative colitis (ICD code for 1968-1975=563.1, ninth revision 556.0). The number of first admissions for each year, 1968-1983, was calculated.

\section{VALIDATION OF CODED DIAGNOSIS}

In order to check the validity of the ICD coding and other details, case records of a proportion of the patients were examined. SHIPS data is confidential and patients' clinical details can only be provided to researchers with the consent of the consultant in charge. This was provided for all requests made for the purpose of this project. Hospital Records officers identified individual patients from the coded hospital number. Written permission to examine the case notes was obtained from the relevant consultant. For the majority, the notes were sent to us by post, and remainder were examined by arrangement in the record department of the hospital concerned. The number of case notes missing, destroyed, or lost was determined.

Regional samples comprised all patients from two of the 11 regions of the country, Lothian and Highland. It was also our intention to examine the notes of $10 \%$ of the patients from the rest of Scotland. This was done for Crohn's disease but not for UC, as discussed below. A decision as to whether the coded diagnosis of Crohn's disease or UC was correct was made from examination of the case records by one of us (JRB), using standard diagnostic criteria. $^{78}$

The target group was children aged up to and including 16 years at the onset of symptoms of disease; it was anticipated that the first hospital admission of such patients might be some years later, hence the printout to age 20 years which should allow us to estimate the proportion with delayed hospital admission. These patients will not have been included in the printouts from which incidence was derived.

\section{STATISTICAL ANALYSIS}

The significance of the observed changes in incidence (new cases per million population in the defined age range per year) and of the proportion of incorrect diagnoses between 1968 and 1983 were assessed by the non-parametric Kendall rank correlation method. The $\chi^{2}$ test was used for qualitative data.

\section{Results}

\section{POPULATION DETAILS}

The population aged $\leqslant 16$ years dropped by $18.8 \%$ in the time covered by this study, from 1504714 in 1968 to 1222433 in 1983 (Fig. 1). The population aged 6-16 years fell from 941633 to 835262 over this time.

\section{CASES IDENTIFIED BY SHIPS}

The computer printout for Crohn's disease listed 654 patients. Two hundred and eighty two were aged $\leqslant 16$ as first admission, of whom 96 were potentially eligible for inclusion in the $10 \%$ and regional

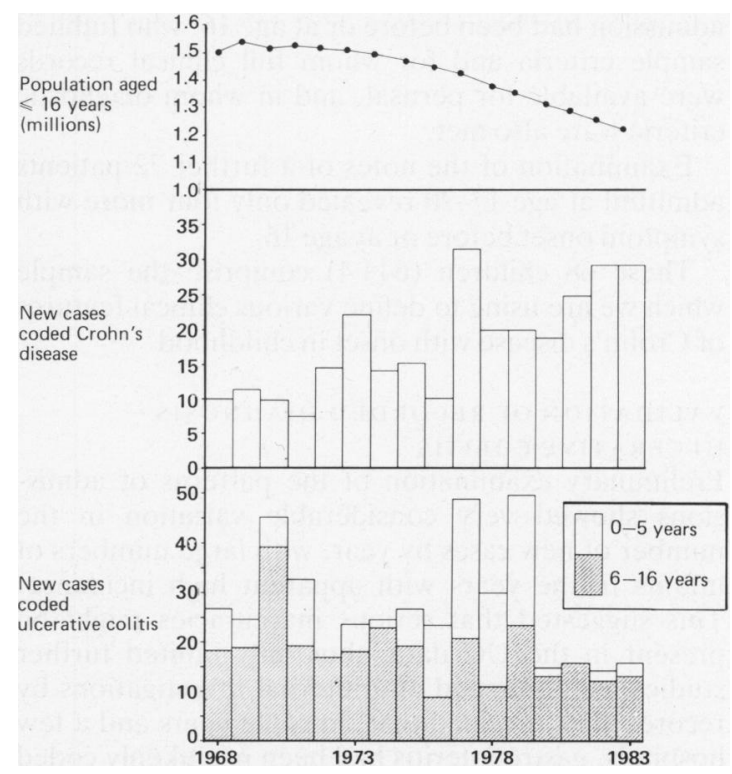

Fig. 1 New cases of Crohn's disease and ulcerative colitis in Scottish children, based on first hospital admissions of $282+$ 441 patients aged $\leqslant 16$; also shown are the population data for Scottish children aged $\leqslant 16$ for the years 1968-1983. 
samples. Similarly, 92 of the 376 patients aged $17-20$ at first admission were eligible.

The printout for UC listed 603 patients. Four hundred and forty one were aged $\leqslant 16$ as first admission. Case note retrieval for UC was confined to the two sample regions to facilitate our joint investigations, with the staff of records departments, of the coding errors which emerged. Thus for UC, 76 were potentially eligible for inclusion in the regional samples. Similarly, of the patients aged 17-20 at first admission 49 were eligible.

No cases referred to or from England, Wales, or Northern Ireland were found.

\section{VALIDATION OF RECORDED DIAGNOSIS - CROHN'S DISEASE}

Table 1 shows the final breakdown of these cases after examination of the case notes. A total of 30 sets of notes were unobtainable - destroyed or lost, and these were evenly distributed throughout the 16 years of the study. Fortunately there were only 10 lost records in the critical age group, up to age 16 . The coded diagnosis of Crohn's disease was judged to be incorrect in $11(13 \cdot 2 \%)$ of the 83 children aged $\leqslant 16$. These cases were evenly distributed throughout the period of study $(p>0.5)\left(\chi^{2}\right.$, one sample test $)$. Of the remaining children, eight did not reside in the target regions and there was an overlap of three children selected both for the $10 \%$ and regional samples. Thus there remained a total of 64 children whose first admission had been before or at age 16, who fulfilled sample criteria and for whom full clinical records were available for perusal, and in whom diagnostic criteria were also met.

Examination of the notes of a further 72 patients admitted at age 17-20 revealed only four more with symptom onset before or at age 16.

These 68 children $(64+4)$ comprise the sample which we are using to define various clinical features of Crohn's disease with onset in childhood.

\section{VALIDATION OF RECORDED DIAGNOSIS -}

ULCERATIVE COLITIS

Preliminary examination of the patterns of admissions showed very considerable variation in the number of new cases by year, with large numbers of infants in the years with apparent high incidence. This suggested that serious inaccuracies might be present in the UC data; thus only limited further studies were pursued and internal investigations by records staff revealed that, in some years and a few hospitals, gastroenteritis had been mistakenly coded as UC. Because the majority of such admissions are of infants and pre-school children we have excluded patients aged $0-5$ years from the incidence calculations below.
Table 1 Breakdown of case-notes sought

\begin{tabular}{|c|c|c|c|c|c|c|}
\hline \multirow{2}{*}{$\frac{\text { Coded diagnosis }}{\text { Age at onset }}$} & \multicolumn{3}{|c|}{ Crohn's disease } & \multicolumn{3}{|c|}{ Ulcerative Colitis } \\
\hline & $\leqslant 16$ & $17-20$ & Total & $\leqslant 16$ & $17-20$ & Total \\
\hline Notes sought & 96 & 92 & 188 & 76 & 49 & 125 \\
\hline Notes found & 86 & 72 & 158 & 61 & 39 & 100 \\
\hline Cases studied & $83^{*}$ & 72 & 155 & 61 & 39 & 100 \\
\hline Wrong diagnosis & 11 & 20 & 31 & 13 & 4 & 17 \\
\hline Geographically unsuitable & 8 & 7 & 15 & 11 & 9 & 20 \\
\hline Confirmed diagnosis & 64 & 45 & 109 & 37 & 26 & 63 \\
\hline $\begin{array}{c}\text { Confirmed diagnosis } \\
\text { with onset } \leqslant 16 \text { yr }\end{array}$ & 64 & 4 & 68 & 37 & 0 & 37 \\
\hline
\end{tabular}

*Overlap of samples - duplicate registration of three patients.

Table 1 shows the final breakdown of patients for whom cases notes were examined. A total of 25 sets of notes were unobtainable - evenly distributed in time. Fifteen were records in the critical $\leqslant 16$ age group. For this group the coded diagnosis was incorrect in 13 of the remaining children, and 11 did not reside in the target regions. Thus there remained a total of 37 children whose first admission with UC had been before or at age 16, who fulfilled sample criteria, for whom full clinical records were available for perusal, and in whom diagnostic criteria were also met. Examination of the notes of a further 39 patients admitted at age 17-20 revealed no more children with UC who had symptom onset before or at age 16 .

These 37 children comprise the sample which we are using to define various clinical features of UC with onset in childhood.

\section{SUBGROUP COMPARISONS}

Further demographic and clinical data extracted from the notes showed no differences between the one in 10, the Lothian, and the Highland subgroups

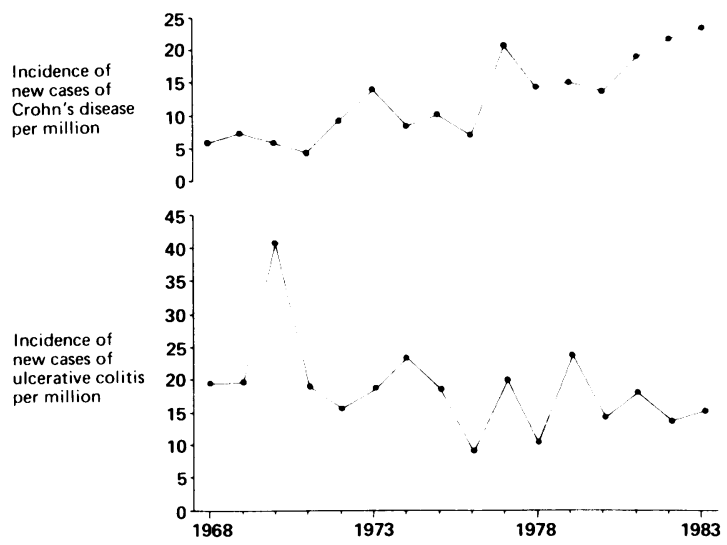

Fig. 2 Age specific incidences of Crohn's disease and ulcerative colitis in Scottish children aged $\leqslant 16$ years for Crohn's disease, and aged six to 16 for ulcerative colitis. 
Table 2 Sex-specific annual incidence rates per million children

\begin{tabular}{|c|c|c|c|c|c|c|c|c|}
\hline \multirow{3}{*}{$\begin{array}{l}\text { Age } \\
\text { Year }\end{array}$} & \multicolumn{4}{|c|}{$\begin{array}{l}\text { Crohn's disease } \\
\leqslant 16\end{array}$} & \multicolumn{4}{|c|}{$\begin{array}{l}\text { Ulcerative colitis } \\
6-16\end{array}$} \\
\hline & \multicolumn{2}{|c|}{ Males } & \multicolumn{2}{|c|}{ Females } & \multicolumn{2}{|c|}{ Males } & \multicolumn{2}{|c|}{ Females } \\
\hline & $n$ & Rate & $n$ & Rate & $n$ & Rate & $n$ & Rate \\
\hline 1968 & 7 & $9 \cdot()$ & 3 & $4 \cdot 1$ & 9 & 18.4 & 9 & $19 \cdot 6$ \\
\hline 1969 & 9 & $11 \cdot 6$ & 2 & $2 \cdot 7$ & 10 & $20 \cdot 4$ & 9 & $19 \cdot 3$ \\
\hline 1970 & 5 & $6 \cdot 4$ & 5 & $6 \cdot 8$ & 24 & $48 \cdot 3$ & 16 & $33 \cdot 8$ \\
\hline 1971 & 4 & $5 \cdot 1$ & 3 & $4 \cdot 1$ & 13 & $25 \cdot 8$ & 6 & $12 \cdot 5$ \\
\hline 1972 & 7 & $9 \cdot 0$ & 7 & $9 \cdot 5$ & 10 & 19.7 & 6 & $12 \cdot 4$ \\
\hline 1973 & 12 & $15 \cdot 6$ & 10 & $13 \cdot 6$ & 11 & 21.5 & 5 & $10 \cdot 3$ \\
\hline 1974 & 8 & $10 \cdot 5$ & 5 & $6 \cdot 9$ & 12 & $23 \cdot 4$ & 6 & $12 \cdot 2$ \\
\hline 1975 & 6 & $8 \cdot 0$ & 9 & $12 \cdot 6$ & 10 & $19 \cdot 5$ & 9 & 18.4 \\
\hline 1976 & 6 & $8 \cdot 1$ & 4 & $5 \cdot 7$ & 3 & 5.9 & 6 & $12 \cdot 3$ \\
\hline 1977 & 21 & $29 \cdot 1$ & 10 & $14 \cdot 5$ & 8 & 15.7 & 13 & $26 \cdot 8$ \\
\hline 1978 & 11 & $14 \cdot 2$ & 9 & 13.4 & 5 & 9.9 & 6 & $12 \cdot 6$ \\
\hline 1979 & 10 & $14 \cdot 5$ & 10 & $15 \cdot 2$ & 16 & $32 \cdot 5$ & 7 & 14.9 \\
\hline 1980 & 9 & $13 \cdot 3$ & 9 & $10 \cdot 9$ & 4 & $8 \cdot 4$ & 9 & $19 \cdot 8$ \\
\hline 1981 & 11 & $16 \cdot 7$ & 14 & $22 \cdot 4$ & 7 & $15 \cdot 2$ & 9 & 20.5 \\
\hline 1982 & 14 & $21 \cdot 8$ & 14 & $22 \cdot 9$ & 6 & $13 \cdot 5$ & 6 & $14 \cdot 2$ \\
\hline 1983 & 17 & $27 \cdot 1$ & 11 & $18 \cdot 5$ & 5 & $11 \cdot 7$ & 8 & 19.7 \\
\hline
\end{tabular}

in terms of age at onset, delay in diagnosis, disease distribution, drug therapy, morbidity or mortality when subgroup analysis was carried out.

FIRST ADMISSION TO HOSPITAL WITH A DIAGNOSIS OF CROHN'S DISEASE AT AGE $\leqslant 16$ YEARS

In 1968 there were 10 first admissions with Crohn's disease recorded, giving an incidence of $6.6 \mathrm{per}$ million. In 1983 there were 28 such admissions, an incidence of 22.9 per million (Figs 1,2 ). Thus, the incidence has increased more than threefold, $\mathrm{r}=0.846, \mathrm{p}<0.0001)$. When analysed separately by sex there was no significant difference in the incidence rates between male and female children (Table 2).

PREVALENCE OF CROHN'S DISEASE IN SCOTTISH CHII.DREN IN 1983

From our unpublished study of clinical features, there is information on age distribution at presentation - the majority of children have onset of symptoms and first admission after the age of eight. By combining data on age distribution and year-by year incidence we estimate that in the last year covered by this study, 1983, there were 116 children in Scotland aged $\leqslant 16$, who had required one or more admissions to hospital with Crohn's disease.

FIRST ADMISSION TO HOSPITAL WITH A DIAGNOSIS OF ULCERATIVE COLITIS AT AGE SIX TO 16 YEARS

In 1968 there were 18 first admissions with UC recorded in the six to 16 age group (Fig. 1). We have used the population aged six to 16 to calculate an approximate incidence of 19.1 per million. In 1983 there were 13 such admissions, an incidence of 15.6 per million. Thus, the incidence has not changed significantly, $r=-0.48, p=0.052$ (Fig. 2). When broken down by sex, however, there is a significant decrease in incidence in boys $(r=-0.4, p=0.028)$ with no change for girls $(r=0 \cdot 1, p=0 \cdot 595)$ (Table 2$)$. We have not attempted to estimate the prevalence of UC.

\section{Discussion}

There are reports from many parts of the world that the incidence of Crohn's disease is changing. A recent analysis of 17 large, well conducted epidemiological studies indicated a continuing rise in incidence in most series, with a few showing a recent plateau after a steady increase in the 1960's and early $1970 \mathrm{~s} .{ }^{x}$ The results presented in this paper, completely unselected data from a country with a population of over five million, suggest that the incidence of Crohn's disease in children increased more than three-fold in the 16 years to 1983 , from 6.6 to 22.9 per million children aged $\leqslant 16$. We estimate that there were 116 children (of a total population of 1.22 million) suffering from Crohn's disease in 1983, a prevalence of $95 \cdot 1$ per million, not dissimilar to the figure of $100 \cdot 7$ per million British children aged $0-18$, derived from a survey conducted on behalf of the British Paediatric Gastroenterology Group." It appears that, in contrast to Crohn's disease, the incidence of ulcerative colitis has not changed significantly between 1968 and 1983 when analysed as a whole. Despite no change in the annual incidence for girls, however (unchanged at 19.6 per million children from 1968 to 1983 ), it does appear that UC is becoming less common in male children (from 18.4 to 11.7 per million children during the study). Although the data are less reliable as discussed, the incidence of UC can be estimated at around 15-19 per million children.

The wrong diagnosis rates of $13 \cdot 2 \%$ for Crohn's disease and $21.3 \%$ for UC seem high but are in keeping with the rates for coding errors of other diseases in SHIPS and Hospital Activity Analysis (J A Clark, personal communication). Mistakes were generally related to errors in clinical diagnosis, subsequently revised rather than being because of clerical factors (Murchison, Barton, and Ferguson, in preparation). To balance this overestimate, some true cases will have been wrongly coded by medical or clerical error. A few children may not have required hospital admission, for example those with mild proctitis or oral Crohn's disease. Examination 
of the notes of 111 patients aged 17 to 20 years at first admission, revealed only four cases who had had the onset of symptoms before the age of 16 , so it seems that the vast majority of children with IBD are diagnosed and initially treated as inpatients. Admissions to non-NHS hospitals are not included in this analysis, but there is very little private paediatric practice in Scotland.

The apparent rise in incidence of Crohn's disease cannot be explained by changes in diagnostic criteria, interval between symptom onset and hospital admission, inter-regional or national referral patterns or the population base. These points have been considered in many papers on the epidemiology of IBD. Our detailed perusal of 258 sets of case notes reveals no evidence of any change in clinical criteria with time. As it is uncommon for IBD to present before the age of seven or eight, a shift in the age profile of the total population of under 16 s could put a higher number of children at risk recently. Examination of population data shows that although the proportion of children aged eight to 16 increased in the early yeàrs of the study period, this peaked in 1977 and has fallen steadily since then. It seems unlikely that the incidence is influenced by diagnostic delay since the median delay in our sample was 4.8 months $(C D)$ and 2.0 months (UC) and mean follow-up was $7 \cdot 2$ years (unpublished observations).

The results of this study of incidence, and our related work on clinical features of IBD presenting in childhood, have serious implications for both doctors and patients. The aetiologies of these diseases are unknown, the conditions run an unpredicatable clinical course and optimal management requires integration of medical and surgical care; in children, growth, sexual maturation, educational and psychological aspects must also be considered. The transition from child to adult health services has been examined in a group of disabled young people in England; the findings indicate failure to ensure continuity of care and practical support. ${ }^{10}$ What is the analogous situation for children with IBD? At what age, and to whom, should the paediatrician transfer clinical responsibility? Do gastroenterologists and surgeons pay sufficient attention to nutrition and growth, aspects which are integral to any paediatric consultation? Will the longterm outcome of these children improve if they are investigated and treated in dedicated adolescent units? Are there medical benefits of follow up in a specialist referral centre which outweigh the social and emotional disadvantages of admission to a hospital far from home? The clinical study of Scottish children with Crohn's disease and UC should provide answers to at least some of these points.

We thank the many clinicians who allowed us to examine records of their patients, and the staff of medical records departments in hospitals throughout Scotland who freely provided assistance with this project. We also acknowledge the help and advice of Dr J Webb and her staff in the Common Services Agency. This work is supported by a grant from CICRA (Crohn's in Childhood Research Appeal).

\section{References}

1 British Paediatric Association. Report of the working party on the needs and care of adolescents. London: British Paediatric Association, 1985.

2 Booth IW, Harries JT. Inflammatory bowel disease in childhood. Gut 1984; 25: 188-202.

3 Ferguson A. Crohn's disease in children and adolescents. J R Soc Med 1984; 77 [suppl 3]: 30-4.

4 Sanderson IR, Walker-Smith JA. Crohn's disease in childhood. Br J Surg 1985; 72: 87-90.

5 Heasman MA. Scottish Hospitals in-patients statistics sources and uses. Health Bull 1968; 26: 10-8.

6 Heasman MA, Clarke JA. Medical record linkage in Scotland. Health Bull 1979; 37: 97-103.

7 Garland CF, Lilienfeld AM, Mendeloff AI, Markowitz JA, Terrell KB, Garland FC. Incidence rates of ulcerative colitis and Crohn's disease in fifteen areas of the United States. Gastroenterology 1981; 81: 1115-24.

8 Calkins BM, Lilienfeld AM, Carland CF, Mendeloff AI. Trends in incidence rates of ulcerative colitis and Crohn's disease. Dig Dis Sci 1984; 29: 913-20.

9 Ferguson A, Rifkind EA, Doig CM. Prevalence of chronic inflammatory bowel disease in British children. In: McConnell RB, Rozen P, Langman MJS, Gilat T, eds. The genetics and epidemiology of inflammatory bowel disease (Front gastrointest res 11). Basel: Karger, 1986: 68-72.

10 Parker G, Hirst M. Continuity and change in medical care for young adults with disabilities. $J R$ Coll Physicians Lond 1987; 21: 129-33. 